\title{
Schooling for Digital Citizens
}

\author{
Najah A. R. Ghamrawi \\ Department of Educational Psychology, Faculty of Education, Lebanese University, Beirut, Lebanon \\ Email: najahghamrawi@hotmail.com
}

How to cite this paper: Ghamrawi, N. A. R. (2018). Schooling for Digital Citizens. Open Journal of Leadership, 7, 209-224. https://doi.org/10.4236/ojl.2018.73012

Received: August 9, 2018

Accepted: August 24, 2018

Published: August 27, 2018

Copyright $\odot 2018$ by author and Scientific Research Publishing Inc. This work is licensed under the Creative Commons Attribution International License (CC BY 4.0).

http://creativecommons.org/licenses/by/4.0/

\begin{abstract}
This study explored the Lebanese teachers' perceptions regarding their knowledge, practice and self-efficacy pertaining to digital citizenship. Data were collected from 378 teacher participants from public schools in Beirut, Lebanon. The study used mixed methods employing an adapted form of Rible's (2015) survey on digital citizenship, alongside a structured focus group interview with 8 teachers drawn randomly from the pool of participant schools. Findings suggest that Lebanese teachers have dispersed and unbalanced perceptions of the concept of digital citizenship, limited practice, and recessive self-efficacy. The study recommends that successful endeavours towards establishing efficient digital citizenship should start with the reconstruction of teachers' knowledge and level of awareness pertaining to digital citizenship.
\end{abstract}

\section{Keywords}

Digital Citizenship, School Effectiveness, Teacher Self-Efficacy, Educational Technology, School Improvement

\section{Introduction}

In an era that is best described as being a digital age; information and communication technology (ICT) has impacted nearly all aspects of life (Shal, El Kibbi, Ghamrawi, \& Ghamrawi, 2018). Individuals of all ages are massively using digital tools for communication, entertainment, accessing and sharing information (Ayetkin, 2013). As a matter of fact, Internet is now seen as less of a tool and more of an extension to human life (Chiang \& Lee, 2011; Shal et al., 2018).

The Internet usage has become worldwide used not only for professional needs but also for student educational pursuits (Biladeau, 2009; Shal et al., 2018). Studies have shown that it has influenced students at the level of their entire development (Bouhnik \& Deshen, 2013) and has transformed them into "digital 
citizens" who are able to use the internet regularly and effectively (Mossberger, Tolbert, \& McNeal, 2011). However, students, or digital citizens, who are very comfortable using digital tools, do not seem to understand the complexities and risks that are associated with such usage (James et al., 2010) and have consequently required a novice schooling demand to educate them for an era of "digital citizenship" (Mossberger, Tolbert, \& McNeal, 2011). Reid \& Boyer (2013) defined digital citizenship as the use of digital tools in respectful, safe, and productive manners with regard to one's self as well as others.

Unfortunately, schools seem to be disregarding the mission of educating their students in terms of digital citizenship, a role which they tend to view as external to schooling and school authority (Orth \& Chen, 2013). However, schools that have incorporated digital citizenship into their learning environments are proving success in building healthy physical and digital cultures for their students (Shipley, 2011).

Research on effective schooling for digital citizenship has highlighted the expansion of character education to include digital citizenship as early as kindergarten (Ribble, 2008). Effective digital citizenship nurtures students to authentically practice the desirable behavior (Tan, 2011) through a curriculum that is best described by Ribble \& Bailey (2007) to include nine areas of behavior: access, commerce, communication, literacy, etiquette, law, rights and responsibilities, health and wellness, security.

Moreover, research has indicated a positive correlation between student motivation towards digital citizenship and the role of teachers in educating for digital citizenship (Klassen \& Chiu, 2010). According to the researcher knowledge and despite the importance of this topic, it is uncommon to identify studies that focused on digital citizenship within the Lebanese educational context and particularity regarding the teachers' perceptions on the instruction of digital citizenship to students.

If schools remain passive, digital culture will proceed in establishing its own norm dominancy without the active role of the school systems that are in charge of guiding the development of its citizens (Hollandsworth, Dowdy, \& Donovan, 2011).

\subsection{Purpose of the Study}

The ability of the twenty first century students to practice digital citizenship is highly impacted by teacher perceptions regarding it (Berardi, 2015). The purpose of this study was to explore the Lebanese public school teachers' knowledge, practice and self-efficacy pertaining to digital citizenship. In this line, this study surveyed teachers' perceptions on the value of instruction targeting the nine areas of digital citizenship as identified in the literature (Ribble \& Bailey, 2007). Particularly, this study was guided by the following research questions:

1) To what extent are the teachers knowledgeable of the term digital citizenship? 
2) What are the teachers' perceptions on the value of instruction for the nine elements targeting digital citizenship?

3) What are teachers' actual practices in educating their students on digital citizenship?

4) How do teachers describe their self-efficacy pertaining to teaching for digital citizenship?

\subsection{Importance of the Study}

Educating children for the era of digital age is not only the responsibility of their caregivers. Dewey (1929) once asserted that a child should be educated according to the needs of its environment, and while the communities in the twentieth century had limited demands for cultivating for face to face citizenships, it is evident that the twenty first century communities have expanded necessities for educating for digital citizenship (Fong, 2015).

Schools of the digital age are responsible for developing students holistically, that is to address the fact that learners are influenced by both digital and physical realms (Ohler, 2012). Furthermore, teachers of the digital age are expected to be trained for digital citizenship instruction (Adalsteinsson, Frimannsdottir, \& Konradsson, 2014). If teachers consider digital citizenship of low value ormanifest a low self-efficacy, it is more likely that their instruction pertaining to digital citizenship is ineffective (Adalsteinsson, Frimannsdottir, \& Konradsson, 2014). Understanding teachers' recent perspectives may lead to the identification of preliminary needs prior to setting up schools focusing on digital citizenship.

Contemporary research has been carried out to explore teachers' perceptions towards digital citizenship, however and to the knowledge of the researcher, there is an evident lack of research examining Lebanese teachers' views concerning digital citizenship. Thus, this study is of value to both national and international readership. With a better understanding of digital citizenship, teachers and schools can function more effectively in educating students for the demands of safe digital communities.

\section{Review of Related Literature}

\subsection{The Digital Natives}

"Digital Natives" is a term described by Mark Prensky for all the individuals who have utilized computer based technology throughout their lives, and whose intellectual processes have adapted based upon the ability to use digital tools (Bittman et al., 2011).

Many scholars affirmed the influence of technology on digital age students, and considered them to be as typical "digital natives" since they spend more time with their digital affairs than they do with their families or in school, which definitely influences their socio-emotional, mental, and physical development to the extent that they have become under the authority of an "other parent" (Orth \& Chen, 2013). 
Recent literature has suggested that digital age students perceive the Internet as a preferred point of origin for most tasks (Atif, 2012), but while "their usage of technology is as common as a knife and fork" (Williams, Crittenden, Keo, \& McCarty, 2012: p. 128), they are often unaware of the potential power they are discharging (Salajan, Schonwetter, \& Cleghorn, 2010); and they are not necessarily good users of the media that they have at their service (Kirschner \& Karpinski, 2010). In addition, digital age students are unconscious of their digital foot print which is a permanent record that is easily searchable by others and impossible to discard (Fong, 2015). Thus, they need to be educated to "be intelligent receivers of information as well as positive contributors" (Fong, 2015: p. 21).

It is imprecise to link the increase of online usage with only negative outcomes, as the internet can yield enriching outcomes (Tan, 2011), if it was practiced safely and responsibly (O'Brien, 2010; Shal et al., 2018). It is evident that students benefit from the online opportunities of collaboration and communication (Collier, 2009), however, they need to practice digital citizenship, an indispensible piece of citizenship education, which teaches students how to be negative and positive web contributions (Fong, 2015). Digital citizenship is best implemented with purposeful adult interaction, teachers and parents, in order to help students discriminate appropriate digital behaviors based upon the impact they will have on one's self, the connected individuals and environments' (Waycott et al., 2009).

\subsection{The Need for Digital Citizenship}

Digital citizenship can be defined as "the norms of appropriate, responsible behaviour with regard to technology use" (Oxley, 2010) and is considered as a mandatary element in the $21^{\text {st }}$ century's education (Greenhow, Robelia, \& Hughes, 2009), since without effective education on digital citizenship, the Web 2.0 will corrupt (Fong, 2015).

Citizenship education of the digital era is engrossing students in the online world (Seo et al, 2013) and inducing an urgent need for students to possess, in addition to the citizenship skills of the physical world, the citizenship skills of the online digital world (Ribble \& Bailey, 2007). It is obvious that students of the recent era need to be taught the skills necessary for safety and responsible use of technology (Yilmaz, 2011). Digital citizenship is by now a crucial element of citizenship education that teaches awareness of negative and positive web contributions.

The literature highlights four main negative aspects for students' digital contributions: cyberbullying, online shaming, online identity, and digital footprints (Yilmaz, 2011). Hinduja \& Patchin (2010) defined cyberbullying as the willful and repeated harm inflicted through the use of electronic devices. It is a new platform for bullying (Cassidy el. al, 2013), but it differs from face to face bullying by: lacking the empathy towards the bullied as it happens remotely, being anonymous, publicly spreading among a huge audience. Digital citizenship need not only educate students about cyberbullying but also to empower them with 
character values, critical thinking, online safety, and the necessary personal online awareness to avoid such situations (Cassidy et al., 2013). Secondly, online shaming which involved generating a digital society where people are labeled without the usual form of inquiry is a common problem (Fong, 2015). Digital citizenship entails scientific inquiry and systematic identification and labelling of news as being fake or trustworthy (Yilmaz, 2011).

The third issue is the possession of two identities: a real life identity and an online identity (Yilmaz, 2011). Online identities result from contributing to the online world by posting media, writing blogs, and collaborating in online chatting (Ribble, 2012). Online identities are critical as they are persistent, searchable, replicable and often visited by invisible audience (Boyd, 2007). Students are unaware that every online activity is recorded as part of their digital footprint that is nearly impossible to retrieve and becomes a permanent part of their online identity (Moore \& Msn, 2012).

Although digital citizenship addresses the negative aspects of the online world; it also targets the benefits of online collaboration and communication, making digital citizenship not only a concept that addresses negative behaviours but also a stimulator of positive repertoire of practice (Collier, 2009). As students' physical lives and online lives have become interconnected, citizenship education is equally important in both worlds but needs to be developed and customized in a way to fit the digital lives of students (Ohler, 2012), and that's why digital citizenship education is a need for contemporary schooling (Yilmaz, 2011).

\subsection{The Three Domains of Digital Citizenship}

Ribble (2012) has identified nine elements of digital citizenship after reviewing the necessary literature and evaluating the findings of various studies. Ribble \& Bailey (2007) sorted the nine elements of digital citizenship under three domains: 1) Respect Yourself and Others: 2) Educate Yourself and Others and 3) Protect Yourself and Others.

The first domain targets: 1.1) the digital access; the full electronic participation in society, 1.2) the digital etiquette; the electronic standards of conduct or procedure, 1.3) the digital law; the electronic responsibility for actions and deeds

The second domain targets: 2.1) the digital commerce; the electronic buying and selling of goods, 2.2) the digital communication; the electronic exchange of information, 2.3) the digital literacy; the process of teaching and learning about technology and the use of technology.

The third domain targets: 3.1) the digital rights and responsibilities; the requirements and freedoms extended to everyone in a digital world, 3.2) the digital health and wellness; the physical and psychological well-being in a digital technology world, 3.3) the digital security and safety; the electronic precautions to guarantee safety.

These nine elements for digital citizenship seem to incorporates all components of Web 2.0 that students often face as they grow from children exploring 
the realms of technology, to teens who communicate and expand their lives (Fong, 2015). Also, it is believed that digital citizenship and citizenship should be instructed as one; as the values we infuse through citizenship teaching will automatically lead to digital citizenship (Collier, 2009).

\subsection{Schooling for Digital Citizenship}

The majority of schools worldwide, and the Lebanese schools do not seem to be any exception, are unaware of the contemporary needs of education to digital citizenship (Orth \& Chen, 2013). However, some schools have started to educate students to be effective digital citizens (Tan, 2011) through creating learning environments that naturally integrates the skills of digital citizenship, and research findings from studies carried on such schools have recorded success in building healthy digital cultures (Shipley, 2011).

Teachers who value digital citizenship and show self-efficacy in instructing for digital citizenship are more likely to motivate students to embrace digital citizenship (Ertmer et al., 2012). However, isolated educators are not sufficient for educating for this concept, the collaboration of other educators is the most significant indicator on student success in relation to necessary digital behaviors (Ertmer et al., 2012). Research has verified that student motivation is positively correlated to the unified coherent approach of educators towards digital citizenship and their efficacy to impact student digital skills of citizenship (Klassen \& Chiu, 2010).

The present state of digital citizenship at schools reveals that if schools stay inactive, digital culture will proceed to construct its own norms without the instruction of the school systems that are responsible for the development of its citizens (Hollandsworth, Dowdy, \& Donovan, 2011).

\section{Methodology}

\subsection{The Sample}

The total number of surveys sent to teachers in Lebanese public schools of Beirut district was 600 . Along with a copy of the survey instrument, teachers received a cover letter specifying the purpose of the study, assuring anonymity and explaining how data will be analyzed. Out of the 600 surveys sent, only 391 were returned out of which 13 surveys were incompletely or improperly filled, and therefore only 378 were useful. Thus the sample was comprised of $\mathrm{N}=378$ public school teachers.

\subsection{The Research Instrument}

Participants completed a survey entitled "Digital Citizenship For Teachers" which is an adapted version of a survey constructed by Ribble (2015). The researcher customized the survey to target teachers' perceptions of the nine elements of digital citizenship classified into their corresponding three domains: 1) Respect Yourself and Others: 2) Educate Yourself and Others and 3) Protect 


\section{Yourself and Others.}

The instrument consisted of 4 point Likert scale statements corresponding to four performance areas which are: “(R) Rarely", “(S) Sometimes”, “(O) Often” and "(F) Frequently". A score of 1 indicates the public school teacher rarely agrees on that element; a score of 2 indicates that the public school teacher sometimes agrees on that element; a score of 3 entails that the public school teacher often agrees on that element; and a score of 4 indicates that the public school teacher frequently agrees on that element.

Additionally, public school teachers also completed a section on demographic information within the survey requesting them to specify their gender, age, education, school level and knowledge of concept. The researcher customized the tool and piloted it with a sample of 24 school teachers who were attending a workshop organized by the researcher. Many words were amended after the conduction of the pilot study and hence the instrument was ready for administration with the actual research sample.

Finally, 8 teachers were randomly selected from the pool of participant schools whose responses were more positive on the survey for the purpose of semi-structured interviews. Invites were sent to all schools that sent back the completed questionnaires. 13 schools responded positively about sending one teacher for the purpose of the focused group interviews. In practice, only 8 schools fulfilled their promise. The interview schedule aimed at gaining an indepth understanding of teachers' actual practices in terms of digital citizenship education alongside their self-efficacy in doing that.

\subsection{Methods of Data Analysis}

Quantitative data generated through the survey was analyzed statistically using SPSS 18.0 for windows. Descriptive statistics were used to describe and summarize the properties of the mass of data collected from the respondents. Means scores, standard deviations and percentages were calculated per each item of the survey instrument.

Qualitative data generated through the semi-structured interview was analyzed thematically using thematic-based analysis. Categories and sub-categories were identified and highlighted within the transcription of the interview.

\section{Results}

\subsection{Demographic Data}

The sample was (42.3\%) males, and (57.7\%) females; the majority (25.4\%) were of the age range of [41 - 45] years. Most teachers (96.6\%) had a license degree, and the greatest percentage (47.6\%) taught classes at the elementary school level. The demographic characteristics of participants are presented in Table 1.

\subsection{Research Question 1}

To what extent are the teachers knowledgeable of the term digital citizenship? 
The majority of the sample $(77.1 \%)$ indicated that they knew nothing about the term digital citizenship. It is worth noting that $(69.1 \%)$ of the public school teachers' sample belonged to the age range of [40 and above], as indicated previously in Table 1, so it might be arguable that the sample can be described as being digitally inexperienced, since they were raised in a digital free society, however it is worth mentioning that (100\%) of the sample, including the $(9.5 \%)$ who belonged to the age range [20 - 30] and who were raised in a digital society, replied by (No) when questioned about their knowledge about the terminology of "digital citizenship". Table 2 displays the results of the first research question.

Table 1. Demographic characteristics of participants.

\begin{tabular}{|c|c|}
\hline Gender & Percentage \% \\
\hline Female & 57.7 \\
\hline Male & 42.3 \\
\hline \multicolumn{2}{|l|}{ Age } \\
\hline $20-25$ & 2.9 \\
\hline $26-30$ & 6.6 \\
\hline $31-35$ & 7.7 \\
\hline $36-40$ & 13.8 \\
\hline $41-45$ & 25.4 \\
\hline $46-50$ & 24.9 \\
\hline Above 50 & 18.8 \\
\hline \multicolumn{2}{|l|}{ Education } \\
\hline Bacc or Equivalent & 0.5 \\
\hline License or Equivalent & 96.6 \\
\hline Masters Degree & 2.9 \\
\hline \multicolumn{2}{|l|}{ School Level } \\
\hline Elementary & 47.6 \\
\hline Middle & 31.7 \\
\hline Secondary & 20.6 \\
\hline
\end{tabular}

Table 2. Data related to research question (1) - knowledge of the concept of digital citizenship.

\begin{tabular}{cc}
\hline Knowledge of Digital Citizenship & \\
\hline Yes & 0 \\
Maybe & 3.0 \\
No & 77.1 \\
\hline
\end{tabular}




\subsection{Research Question 2}

What are the teachers' perceptions on the value of instruction for the nine elements targeting digital citizenship?

Data derived from the nine elements of the survey, targeting the three domains of Digital Citizenship, was used to respond to the second research question.

Firstly, the scores obtained from the first digital citizenship domain are presented in Table 3. The data revealed that teachers had a dispersed perspective towards the necessary skills of the three elements targeting the domain of "Respecting self and Others': digital access (72.4\%, sometimes), digital etiquette (55.5\%, often) and digital law (55.8\%, rarely). Secondly, the scores obtained from the second digital citizenship domain are presented in Table 4 . The data revealed that teachers also have diffused understanding of the essential skills of the three elements targeting the domain of "Educating self and Others": digital commerce (36.2\%, rarely), digital communication ( $87.3 \%$, often) and digital literacy (50.25\%, sometimes). Finally, the scores obtained from the third digital citizenship domain are presented in Table 5 . The data revealed that teachers had

Table 3. Data related to research question (2)-Domain 1.

\begin{tabular}{|c|c|c|c|c|c|c|c|c|c|}
\hline Element & Item & Domain of Respect Yourself and Others & & $\mathbf{R}$ & S & $\mathrm{O}$ & $\mathbf{F}$ & $\mathbf{M}$ & std \\
\hline \multirow{3}{*}{$\begin{array}{l}\text { 1) Digital } \\
\text { Access }\end{array}$} & 1.1 & Access technology opportunities within the school. & \multirow{8}{*}{ 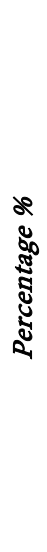 } & 19.6 & 71.7 & 8.7 & 0 & 1.89 & 0.52 \\
\hline & 1.2 & Access technology opportunities outside the school. & & 0 & 54 & 46 & 0 & 2.46 & 0.49 \\
\hline & 1.3 & $\begin{array}{l}\text { Use technology opportunities that are accommodated } \\
\text { with their special needs. }\end{array}$ & & 5 & 91.5 & 3.4 & 0 & 1.98 & 0.29 \\
\hline \multirow{3}{*}{$\begin{array}{l}\text { 2) Digital } \\
\text { Etiquette }\end{array}$} & 2.1 & $\begin{array}{l}\text { Use technology in ways that minimize } \\
\text { the negative effects on others. }\end{array}$ & & 2.4 & 11.6 & 84.6 & 1.9 & 2.85 & 0.45 \\
\hline & 2.2 & Use technology when it is contextually appropriate. & & 5.8 & 83.3 & 6.1 & 4.8 & 2.10 & 0.54 \\
\hline & 2.3 & $\begin{array}{l}\text { Respect others online: not engaging in } \\
\text { cyberbullying, flaming, inflammatory language, and so forth. }\end{array}$ & & 2.4 & 19.8 & 75.9 & 1.9 & 2.77 & 0.51 \\
\hline \multirow{2}{*}{$\begin{array}{l}\text { 3) Digital } \\
\text { Law }\end{array}$} & 3.1 & Use technology the way it was intended. & & 68 & 27.8 & 0 & 4.2 & 1.4 & 0.70 \\
\hline & 3.2 & Use technology without infringing on others' rights. & & 26.2 & 28.8 & 45 & 0 & 2.19 & 0.82 \\
\hline
\end{tabular}

Table 4. Data related to research question (2)-Domain 2.

\begin{tabular}{|c|c|c|c|c|c|c|c|c|c|}
\hline Element & Item & Domain of Educate Yourself and Others & & $\mathbf{R}$ & $S$ & $\mathrm{O}$ & F & $\mathbf{M}$ & std \\
\hline \multirow{2}{*}{$\begin{array}{l}\text { 4) Digital } \\
\text { Commerce }\end{array}$} & 4.1 & $\begin{array}{l}\text { Be aware of the opportunities as well as the problems } \\
\text { associated with purchasing items using digital technology. }\end{array}$ & & 64.8 & 31 & 0 & 4.2 & 1.44 & 0.7 \\
\hline & 4.2 & $\begin{array}{l}\text { Be aware of how to purchase goods and services } \\
\text { through digital formats. }\end{array}$ & de & 7.7 & 19.8 & 59.8 & 12.7 & 2.78 & 0.76 \\
\hline \multirow{2}{*}{$\begin{array}{l}\text { 5) Digital } \\
\text { Communication }\end{array}$} & 5.1 & $\begin{array}{l}\text { Use email, cell phone, texting, and social networking } \\
\text { technologies appropriately when communicating with others }\end{array}$ & $\underset{\mathbb{2}}{\mathbb{3}}$ & 2.1 & 5.3 & 91 & 1.6 & 2.92 & 0.38 \\
\hline & 5.2 & $\begin{array}{l}\text { Be aware of rules, options, and etiquette when using } \\
\text { digital communication technologies }\end{array}$ & 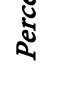 & 5 & 9.8 & 83.6 & 1.6 & 2.86 & 0.53 \\
\hline \multirow{2}{*}{$\begin{array}{l}\text { 6) Digital } \\
\text { Literacy }\end{array}$} & 6.1 & Acquire the skills of using the technology tools in the classroom. & & 76.7 & 17.2 & 4 & 2.1 & 1.31 & 0.65 \\
\hline & 6.2 & $\begin{array}{l}\text { Use digital technologies to take best advantage } \\
\text { of the educational opportunities available to them }\end{array}$ & & 10.1 & 83.3 & 5.3 & 1.3 & 1.98 & 0.45 \\
\hline
\end{tabular}


Table 5. Data related to research question (2).

\begin{tabular}{|c|c|c|c|c|c|c|c|c|c|}
\hline Element & Item & Domain of Protect Yourself and Others & & $\mathbf{R}$ & $S$ & O & $\mathrm{F}$ & M & std \\
\hline 7) Digital & 7.1 & Be aware of their rights when using digital technologies. & \multirow{4}{*}{ 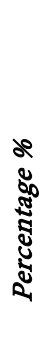 } & 4.2 & 86 & 4.8 & 5 & 2.11 & 0.53 \\
\hline $\begin{array}{l}\text { Rights and } \\
\text { Responsibilities }\end{array}$ & 7.2 & $\begin{array}{l}\text { Be aware of their responsibilities when using } \\
\text { digital technologies. }\end{array}$ & & 4.5 & 79.6 & 4.5 & 11.4 & 2.23 & 0.7 \\
\hline \multirow{2}{*}{$\begin{array}{l}\text { 8) Digital Health } \\
\text { and Wellness }\end{array}$} & 8.1 & $\begin{array}{l}\text { Be aware of the physical dangers that can } \\
\text { accompany the use of digital technology. }\end{array}$ & & 65.9 & 27.8 & 3.7 & 2.6 & 1.43 & 0.69 \\
\hline & 8.2 & $\begin{array}{l}\text { Be aware of the internet addiction that can } \\
\text { accompany the use of digital technology. }\end{array}$ & & 68.5 & 29.1 & 1.6 & 0.8 & 1.35 & 0.55 \\
\hline $\begin{array}{l}\text { 9) Digital } \\
\text { Security }\end{array}$ & 9.1 & $\begin{array}{l}\text { Acquire the necessary literacy to protect } \\
\text { themselves and their equipment from harm. }\end{array}$ & & 23 & 70.9 & 6.1 & 0 & 1.83 & 0.51 \\
\hline
\end{tabular}

an even scattered perception of the vital skills of the three elements targeting the domain of "Protecting self and Others": digital rights and responsibilities (82.8\%, sometimes), digital health and wellness (67.2\%, rarely) and digital security (70.9\%, sometimes).

\subsection{Research Question 3}

What are teachers' actual practices in educating their students on digital citizenship?

Data analyzed for the purpose of responding to this research question was obtained through the focus group interview with teachers from 8 public schools in Beirut. These schools were among the pool of schools that gave more positive answers on the survey instrument. The researcher illustrated the concept of digital citizenship (as per the literature cited previously in this paper) to participants and then asked them to give practical examples on how they came about this concept in their school settings. The thematic analysis of the transcribed data arrived at the following themes presented in Figure 1.

Themes emerging from the focus group interview as presented in Figure 1 indicate some promising findings. Teachers seem to have been using three approaches to dealing with digital citizenship. First, some of them adopted an approach whereby they addressed the elements of the digital citizenship concept only when big problems surfaced their classrooms. In this line, teachers played the role of counselors who tries to make students put themselves in the shoes of other students. Only in those instances teachers came across digital citizenship.

"I address these concepts [digital citizenship] when some kind of bullying on the internet [cyberbullying] surfaces in my classroom" (T3).

"When two or more students start a fight on school campus because of bullying on the internet, I take that very seriously and consider it the best opportunity to address the elements you've mentioned [digital citizenship]" (T7).

"When a problem happens it seems to be the best opportunity for addressing this concept and this is exactly what I do with my students" (T2). 


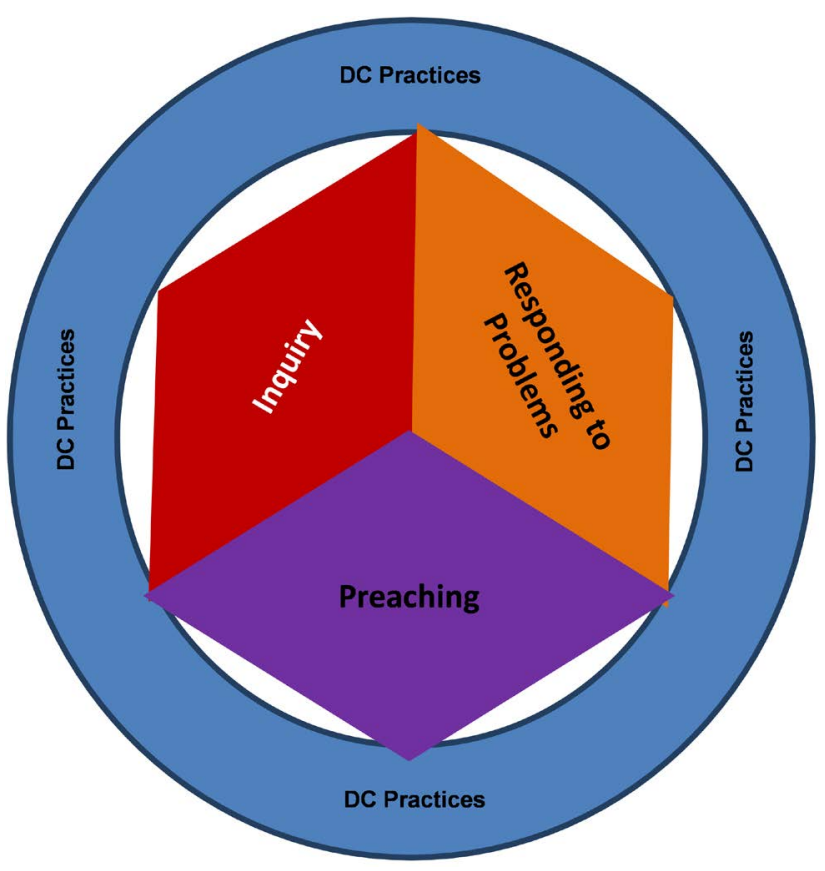

Figure 1. Themes emerging from the focus group interview on digital citizenship practices.

Other teachers though it was part of ethics to preach on the importance of digital citizenship concepts. These teachers did that during teaching social studies.

"When addressing ethics in my classroom I do come across a myriad of things that requires ethical considerations including the concepts underlying digital citizenship. I preach my students on the importance of maintaining respect even when the other person is not standing in front of them" (T1).

"Teaching the concepts of digital citizenship is part of what I do in my social studies class [Tarbiah Madaniah]. I do tell students that it is always important to think of others and not to hurt them even if they were anonymous to others" (T5).

"I preach my students in my class about digital citizenship by telling them about suicidal stories that resulted from bullying on the internet that I come across in the media. As such, I find it very useful for students who get so much attentive because the stories are real ones and they could check them themselves on media" (T8).

Finally, only one teacher (who taught technology) among interviewees described inquiry as being her approach in addressing digital citizenship.

"I would provide my students with a real-life problem and I pose it to them with immense emotions and I ask them to work in groups and try to address what went wrong? what would they do if they were involved in it? And how can this solve this problem" (T4). 


\subsection{Research Question 4}

How do teachers describe their self-efficacy pertaining to teaching for digital citizenship?

Self-Efficacy was illustrated to teachers as being a term that describes the personal view of self ability to attain targeted mission. It is influenced by previous experiences of "success, watching others succeed, the encouragement provided by others, and one's physical and emotional well-being" (Adalsteinsson, Frimannsdottir, \& Konradsson, 2014).

When teachers were asked to rate their self-efficacy on a scale of 1 to 10 (10 being the highest possible score) pertaining to the effective handling of the digital citizenship concept in their schools. Only one of them gave herself a score of 5/10; while all the rest gave themselves a score below 5 .

The reasons why they did not feel well about handling digital citizenship effectively in their classrooms were grouped into themes and are represented in Figure 2.

As Figure 2 shows, teachers attributed their low self-efficacy in handling digital citizenship to 4 main factors: lack of knowledge, lack of training, lack of authority and lack of time.

Teachers explained they did not know much and enough about digital citizenship except bullying on the internet.

"Probably it is because we only know about bullying on the internet [cyberbullying]. There are a lot of elements that we were not aware of except when you [the researcher] explained them to us" (T2).

Teachers also spoke of the lack of training they received particularly pertaining to this concept.

"We've never had any training that came across such a concept" (T8).

Teachers believed very little authority about what happened inside school, so how about things that happened outside schools.

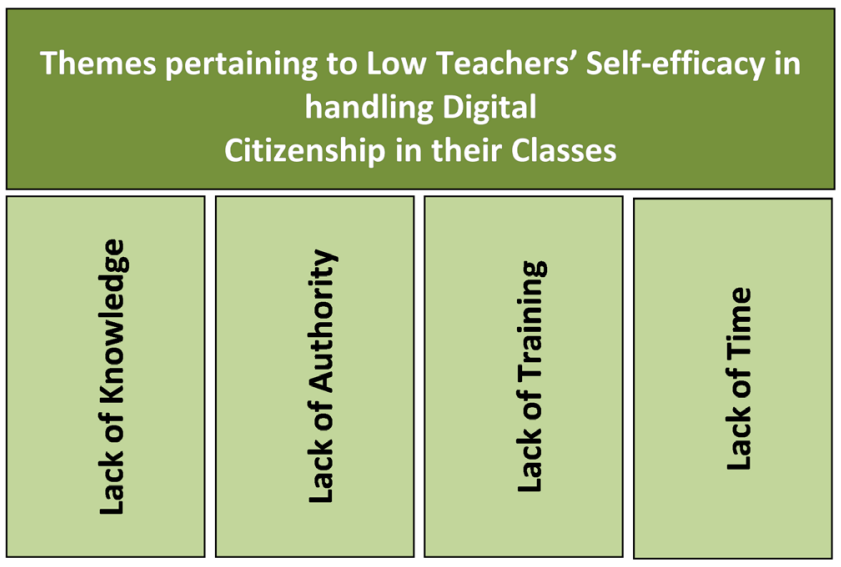

Figure 2. Themes emerging about teachers' low self-efficacy in handling digital citizenship. 
"You know we have very limited authority over our students in school; like deducting grades or sending offensive students to the principal's office; so what authority we do have over activities students carried out outside school. I think we have null authority" (T7).

Finally, teachers spoke of the lack of time as one reason for no addressing the elements of digital citizenship.

"I think we really are short on time. We cannot address all problems we encounter because we have curricula to cover and we would get penalized if we get late." (T1).

\section{Summary and Conclusion}

This study investigated the Lebanese teachers' perception of digital citizenship; an area of research that, to the knowledge of the researcher, has been little addressed in Lebanon and the Arab region. Findings indicate that teachers were unaware of the term "digital citizenship" and its corresponding nine necessary elements.

Teachers' knowledge of digital citizenship was almost null and their repertoire of practice was never better than their knowledge level. Teachers' practices were limited to occasional preaching, situational addressing to arising problems and only one teacher in the whole sample reported the creation of authentic learning opportunities she offered to her students within the context of teaching technology. In addition, teachers revealed a low level of self-efficacy in handling digital citizenship. They attributed this to the lack of knowledge, training, time and authority.

The uncertainty of Lebanese teachers' perspectives towards the key concepts of digital citizenship inhibits the development of students as actual digital citizens, since teachers play a major role in instructing for an effective implementation of digital citizenship (Ohler, 2012). Any schooling reform towards an efficient digital citizenship would start with the reconstruction of teachers' perspectives for the necessary elements of digital citizenship (Ribble, 2015).

With the current status quo of the Lebanese schools, digital communities and cultures would grow wildly without any control as per Klassen \& Chiu (2010) or Hollandsworth, Dowdy, \& Donovan (2011). As Yilmaz (2011) or Ohler (2012) suggest; this could be an introduction towards severe schooling problems.

\subsection{Limitations}

This study is confronted with a number of methodological limitations which restricts the extrapolation of its results. The first one of them all is the size of the sample involved in this study. In addition, the criteria used for selecting the schools were limited to the ease of accessing schools; mainly the district of Beirut. Also, the research instrument might manipulate respondents perceptions as it suggests specific skills for the nine elements of digital citizenship. In addition, 
only 8 teachers took part in the focus group interview which entails that the results may never be generalized.

\subsection{Recommendations}

This study was limited to public schools in Beirut. It would be informative if future research employs a more representative sample of schools from across the country. The involvement of private schools would give a more comprehensive picture of the reality of digital citizenship in schools. Besides, geographic dispersion would be beneficial allowing for schools for the various governorates of Lebanon to take part. In addition, conducting a similar study focused on the administrators and/or community stakeholders would be more informative. Also, it would be beneficial to perform case studies on techniques successfully employed by administrators, technology staff, and teacher technology leaders that have resulted in increased self-efficacy, and digital citizenship instruction. Finally, studying digital citizenship implemented through character education programs would result in a more comprehensive approach towards an effective schooling towards digital citizenship.

\section{Conflicts of Interest}

The authors declare no conflicts of interest regarding the publication of this paper.

\section{References}

Adalsteinsson, R. I., Frimannsdottir, I. B., \& Konradsson, S. (2014). Teachers' Self-Esteem and Self-Efficacy. Scandinavian Journal of Educational Research, 58, 540-550. https://doi.org/10.1080/00313831.2013.773559

Atif, Y. (2012). Conversational Learning Integration in Technology Enhanced Classrooms. Computers in Human Behavior, 29, 416-423.

https://doi.org/10.1016/j.chb.2012.07.026

Ayetkin, I. (2013). Digital Citizenship. The Turkish Online Journal of Educational Technology, 13, issue 1 .

Berardi, R. (2015). Digital Citizenship: Elementary Educator Perceptions and Formation of Instructional Value and Efficacy. A Dissertation submitted to the Faculty of Immaculata University, Immaculata, PA.

Biladeau, S. (2009). Technology and Diversity: Perceptions of Idaho's Digital Natives. Teacher Librarian, 36, 1-3.

Bittman, M., Rutherford, L., Brown, J., \& Unsworth, L. (2011). Digital Natives? New and Old Media and Children's Outcomes. Australian Journal of Education, 55, 161-175. https://doi.org/10.1177/000494411105500206

Bouhnik, D., \& Deshen, M. (2013). Unethical Behavior of Youth in the Internet Environment. The International Journal of Technology, Knowledge, and Society, 9, 109-124. https://doi.org/10.18848/1832-3669/CGP/v09i02/56372

Boyd, D. M. (2007). Why Youth (Heart) Social Network Sites: The Role of Networked Publics in Teenage Social Life. MacArthur Foundation Series on Digital Learning-Youth, Identity, and Digital Media, 7641, 1-26. 
Cassidy, W., Faucher, C., \& Jackson, M. (2013). Cyberbullying among Youth: A Comprehensive Review of Current International Research and Its Implications and Application to Policy and Practice. School Psychology International, 34, 575-612. https://doi.org/10.1177/0143034313479697

Chiang, L., \& Lee, B. (2011). Ethical Attitude and Behaviors Regarding Computer Use. Ethics and Behavior, 21, 481-497. https://doi.org/10.1080/10508422.2011.622181

Collier, A. (2009). A better Safety Net. School Library Journal, 55, 36. https://eric.ed.gov/?id=EJ863362

Ertmer, P. A., Ottenbreit-Leftwich, A. T., Sadik, O., Sendurur, E., \& Sendurur, P. (2012). Teacher Beliefs and Technology Integration Practices: A Critical Relationship. Computers and Education, 59, 423-435. https://doi.org/10.1016/j.compedu.2012.02.001

Fong, J. (2015).New Citizenship for a Digital Age: 21st Century Digital Citizenship Education. Master Thesis, Victoria, BC: University of Victoria.

Greenhow, C., Robelia, B., \& Hughes, J. E. (2009). Learning, Teaching, and Scholarship in a Digital Age: Web 2.0 and Classroom Research: What Path Should We Take Now? Educational Researcher, 38, 246-259. https://doi.org/10.3102/0013189X09336671

Hinduja, S., \& Patchin, J. W. (2010). Bullying, Cyberbullying, and Suicide. Archives of Suicide Research, 14, 206-221. https://doi.org/10.1080/13811118.2010.494133

Hollandsworth, R., Dowdy, L., \& Donovan, J. (2011). Digital Citizenship in K-12: It Takes a Village. TechTrends, 55, 37-47. https://doi.org/10.1007/s11528-011-0510-Z

James, C., Davis, K., Flores, A., Francis, J. M., Pettingill, L., Rundle, M., \& Garnder, H. (2010). Young People, Ethics, and the New Digital Media. Contemporary Readings in Law and Social Justice, 2, 215-284.

Kirschner, P. A., \& Karpinski, A. C. (2010). Facebook and Academic Performance. Computers in Human Behavior, 26, 1237-1245. https://doi.org/10.1016/j.chb.2010.03.024

Klassen, R. M., \& Chiu, M. M. (2010). Effects on Teachers' Self Efficacy and Job Satisfaction: Teacher Gender, Years of Experience, and Job Stress. Journal of Educational Psychology, 102, 741-756. https://doi.org/10.1037/a0019237

Moore, S. C., \& Msn, R. N. (2012). Digital Footprints on the Internet. International Journal of Childbirth Education, 27, 86-91.

Mossberger, K., Tolbert, C. J., \& McNeal, R. S. (2011). Digital Citizenship: The Internet, Society, and Participation. Cambridge, MA and London: The MIT Press.

O’Brien, T. (2010). Creating Better Digital Citizens. The Australian Educational Leader, $32,1-2$.

Ohler, J. (2012). Digital Citizenship Means Character Education for the Digital Age. Education Digest, 77, 14-17.

Orth, D., \& Chen, E. (2013). The Strategy for Digital Citizenship: Guiding Our Children in a Digital World. National Association of Independent Schools, 72, 56-63.

Oxley, C. (2010). Digital Citizenship: Developing an Ethical and Responsible Online Culture. In Diversity Challenge Resilience: School Libraries in Action Proceedings of the 12th Biennial School Library Association of Queensland (pp. 1-11). Brisbane, QLD, Australia. http://files.eric.ed.gov/fulltext/ED518512.pdf

Reid, G. G., \& Boyer, W. (2013). Social Networking Sites and Young Adolescent Identity Development. Childhood Education, 89, 243-253. https://doi.org/10.1080/00094056.2013.815554

Ribble, M. (2008). Passport to Digital Citizenship: Journey toward Appropriate Technology Use at School and Home. Learning \& Leading with Technology, 36, 14-17. 
Ribble, M. (2012). Digital Citizenship for Educational Change. Kappa Delta Pi Record, 48, 148-151. https://doi.org/10.1080/00228958.2012.734015

Ribble, M. (2015). Digital Citizenship in Schools: Nine Elements All Students Should Know (3rd ed.). Washington DC: International Society for Technology in Education.

Ribble, M., \& Bailey, G. (2007). Digital Citizenship in Schools. Washington DC: ISTE.

Salajan, F. D., Schonwetter, D. J., \& Cleghorn, B. M. (2010). Student and Faculty Inter-Generational Digital Divide: Fact or Fiction? Computers \& Education, 55, 1393-1403. https://doi.org/10.1016/j.compedu.2010.06.017

Seo, H., Houston, J. B., Knight, L. A. T., Kennedy, E. J., \& Inglish, A. B. (2013). Teens' Social Media Use and Collective Action. New Media \& Society, 16, 883-902. https://doi.org/10.1177/1461444813495162

Shal, T., El Kibbi, I., Ghamrawi, N., \& Ghamrawi, N. A. (2018b). Principals' Differentiated Learning through Social Media: Practices and Obstacles. International Journal of Education and Applied Research, 8, 19-29.

Shal, T., El Kibbi, I., Ghamrawi, N., \& Ghamrawi, N. A. R. (2018a). Web 2.0-A Tool for Learning or Socialization Only? Perspectives \& Experiences of Lebanese School Principals. International Journal of Research in Economics and Social Sciences, 8, 315-347. http://euroasiapub.org

Shipley, G. (2011). Cyber Misconduct, Discipline and the Law. Leadership, 41, 14-16.

Tan, T. (2011). Educating Digital Citizens. Leadership, 41, 30-32.

Waycott, J., Bennett, S., Kennedy, G., Dalgarno, B., \& Gray, K. (2009). Digital Divides? Student and Staff Perceptions of Information and Communication Technologies. Computers \& Education, 54, 1202-1211. https://doi.org/10.1016/j.compedu.2009.11.006

Williams, D. L., Crittenden, V. L., Keo, T., \& McCarty, P. (2012). The Use of Social Media: An Exploratory Study of Usage among Digital Natives. Journal of Public Affairs, 12, 127-136. https://doi.org/10.1002/pa.1414

Yilmaz, H. (2011). Cyberbullying in Turkish Middle Schools: An Exploratory Study. School Psychology International, 32, 645-654.

https://doi.org/10.1177/0143034311410262 